\title{
Effects of Various Modes of Mechanical Ventilation in Normal Rats
}

\author{
Matteo Pecchiari, M.D., Ph.D., Ario Monaco, V.M.D., Ph.D., Antonia Koutsoukou, M.D., \\ Patrizia Della Valle, Bc.S., Guendalina Gentile, Bc.S., Edgardo D’Angelo, M.D.
}

\begin{abstract}
Background: Recent studies in healthy mice and rats have reported that positive pressure ventilation delivered with physiological tidal volumes at normal end-expiratory volume worsens lung mechanics and induces cytokine release, thus suggesting that detrimental effects are due to positive pressure ventilation per se. The aim of this study in healthy animals is to assess whether these adverse outcomes depend on the mode of mechanical ventilation.

Methods: Rats were subjected to $4 \mathrm{~h}$ of spontaneous, positive pressure, and whole-body or thorax-only negative pressure ventilation ( $\mathrm{N}=8$ per group). In all instances the ventilatory pattern was that of spontaneous breathing. Lung mechanics, cytokines concentration in serum and broncho-alveolar lavage fluid, lung wet-to-dry ratio, and histology were assessed. Values from eight animals euthanized shortly after anesthesia served as control.

Results: No evidence of mechanical ventilation-dependent lung injury was found in terms of lung mechanics, histology, or wet-to-dry ratio. Relative to control, cytokine levels and recruitment of polymorphonuclear leucocytes increased slightly, and to the same extent with spontaneous, positive pressure, and whole-body negative pressure ventilation. Thorax-only negative pressure ventilation caused marked chest and lung distortion, reversible increase of lung elastance, and higher polymorphonuclear leucocyte count and cytokine levels.

Conclusion: Both positive and negative pressure ventilation performed with tidal volumes and timing of spontaneous, quiet breathing neither elicit an inflammatory response nor cause morpho-functional alterations in normal animals, thus supporting the notion of the presence of a critical volume threshold above which acute lung injury ensues. Distortion of lung parenchyma can induce an inflammatory response, even in the absence of volotrauma. (ANESTHESIOLOGY 2014; 120:943-50)
\end{abstract}

$\mathbf{P}$ OSITIVE pressure mechanical ventilation (PPMV) is widely used as a life-saving intervention, as well as a valuable tool during anesthesia. Nonetheless, this intervention is regarded as potentially harmful even in healthy lungs, when ventilator-induced lung injury can arise from overstretching of lung parenchyma, leading to surfactant inactivation, failure of the alveolar-capillary barrier, and edema, ${ }^{1-3}$ or abnormal stresses due to cyclic opening of closed airways, inducing epithelial necrosis and sloughing and airway-parenchymal uncoupling. ${ }^{4-6}$ Furthermore, ventilator-induced lung injury is usually, ${ }^{6-8}$ though not always, ${ }^{3,9}$ accompanied by the release of proinflammatory cytokines, possibly because of cellular mechano-transduction processes. ${ }^{10,11}$

If overstretching and cyclic airways closing and opening were the major triggers of the pathological cascade of ventilator-induced lung injury, then a safe PPMV would be obtained by using appropriate tidal volumes $\left(\mathrm{V}_{\mathrm{T}}\right)$ and end-expiratory lung volumes (EELV). This task could be challenging or even impossible in the clinical settings, where lung parenchyma is often heterogeneous. ${ }^{12,13}$ However, no harm should result from the PPMV of normal lungs if $\mathrm{V}_{\mathrm{T}}$ and EELV are similar to those of spontaneous, quiet breathing. Indeed, the conclusion has been drawn that ventilation becomes injurious to

\begin{abstract}
What We Already Know about This Topic
- Large tidal volumes used in positive pressure ventilation in normal lungs can cause ventilator-induced lung injury

\section{What This Article Tells Us That Is New}

- Anesthetized rats subjected to positive pressure or negative pressure ventilation with the breathing pattern occurring before mechanical ventilation did not experience ventilatorinduced lung injury, unless marked chest distortion was produced, supporting the hypothesis that with normal lung expansion, there is a critical strain threshold associated with ventilator-induced lung injury
\end{abstract}

normal lungs only above a relatively high, species-dependent $V_{\text {T }}$ threshold, usually greater than $15 \mathrm{ml} / \mathrm{kg}^{3}{ }^{3}$

In contrast to this conclusion, recent studies indicate that a safe threshold in terms of $\mathrm{V}_{\mathrm{T}}$ and EELV does not exist for PPMV. In healthy rats, an increased expression of proinflammatory cytokines has been observed in macrophages of broncho-alveolar lavage fluid (BALF) after $2 \mathrm{~h}$ of PPMV with a $V_{T}$ of $10 \mathrm{ml} / \mathrm{kg},{ }^{14}$ and disruption of the extracellular matrix, with perivascular space engorgement,

Submitted for publication April 24, 2013. Accepted for publication October 17, 2013. From the Dipartimento di Fisiopatologia Medicochirurgica e dei Trapianti, Università degli Studi di Milano, Milan, Italy (M.P., A.M., and E.D.); 1st Department of Respiratory Medicine, Sotiria Hospital, University of Athens Medical School, Athens, Greece (A.K.); Servizio di Coagulazione e Unità di Ricerca sulla Trombosi, Istituto di Ricovero e Cura a Carattere Scientifico, San Raffaele, Milan, Italy (P.D.V.); and Dipartimento di Scienze Biomediche per la Salute, Università degli Studi di Milano, Milan, Italy (G.G.).

Copyright $($ C 2013, the American Society of Anesthesiologists, Inc. Lippincott Williams \& Wilkins. Anesthesiology 2014; 120:943-50 
cuff formation, and substantial alterations of lung mechanics was found after $4 \mathrm{~h}$ of PPMV with $\mathrm{V}_{\mathrm{T}}$ of $8 \mathrm{ml} / \mathrm{kg}$ and zero end-expiratory pressure. ${ }^{15}$ In normal mice, PPMV with a $V_{\text {T }}$ of 7.5 to $8 \mathrm{ml} / \mathrm{kg}$ and positive end-expiratory pressure of 2 to $4 \mathrm{~cm} \mathrm{H}_{2} \mathrm{O}$ for 4 to $6 \mathrm{~h}$ caused an increased expression in lung tissue homogenates, and higher concentration in serum and BALF of several inflammatory cytokines, ${ }^{16-18}$ besides recruitment of pulmonary granulocytes, ${ }^{16,18}$ moderate lung edema, ${ }^{16,17}$ and increased permeability of the alveolar-capillary barrier. ${ }^{18}$ These studies suggest that even the ventilatory pattern adopted by the spontaneously breathing animal becomes injurious if produced in the anesthetized, paralyzed animal by means of conventional positive pressure ventilators. Indeed, a recent study has shown that in surfactant-depleted, paralyzed rabbits negative pressure ventilation improves oxygenation and lessens parenchymal and airway injury relative to conventional PPMV. ${ }^{19}$

With the aim of assessing whether mechanical ventilation with the $\mathrm{V}_{\mathrm{T}}$ of spontaneous, quiet breathing causes per se detrimental effects on lung functions in normal animals, the outcomes of prolonged spontaneous ventilation (SV) in anesthetized rats have been compared with those obtained with PPMV and negative pressure mechanical ventilation of corresponding duration, negative pressure having been applied either to the whole body (NPwвMV), as in the iron lung, or to the thorax only (NPтоMV), as with cuirass or poncho-like devices.

\section{Materials and Methods}

\section{Animal Preparation}

Forty male Sprague-Dawley rats (weight range, 365 to $440 \mathrm{~g})$ were premedicated with diazepam $(10 \mathrm{mg} / \mathrm{kg})$ and anesthetized with an intraperitoneal injection of pentobarbital sodium $(40 \mathrm{mg} / \mathrm{kg})$ and chloral hydrate $(170 \mathrm{mg} / \mathrm{kg})$. The animals were kept supine and they breathed room air at zero end-expiratory pressure throughout the experiment. The rectal temperature was maintained at $37^{\circ} \mathrm{C}$ with a heating pad. The trachea was cannulated, and a balloon-tipped catheter placed in the lower third of the esophagus, the appropriate positioning of the balloon being tested with the occlusion method. ${ }^{20}$ A pentobarbital (approximately $4 \mathrm{mg} / \mathrm{ml}$ ) saline solution was continuously infused (approximately $8 \mathrm{ml} \mathrm{kg}^{-1} \mathrm{~h}^{-1}$ ) into a tail vein.

The animals were handled according to the National Institute of Health guiding principles. The study was approved by Ministero della Salute, Rome, Italy.

\section{Procedure and Data Analysis}

Airflow, tracheal (Ptr), and esophageal pressure signal were measured, digitized, and stored as previously described. ${ }^{5,6}$ Transpulmonary pressure $\left(\mathrm{P}_{\mathrm{L}}\right)$ was obtained as Ptr-esophageal pressure, and volume changes $(\Delta \mathrm{V})$ by integration of the digitized airflow signal.
The whole experimental procedure is shown in figure 1 . After a 10-min period of SV (point A), the animals were either killed immediately with an overdose of anesthetics (C group) or randomly assigned to one of the four ventilation modes (SV, PPMV, NPwвMV, and NPтоMV group; eight rats each). Animals were paralyzed (fig. 1, squares) with pancuronium bromide $(1 \mathrm{mg} / \mathrm{kg})$, and ventilated with the pattern observed during spontaneous breathing. Adequateness of anesthesia was repeatedly checked from the absence of sudden changes of heart rate and paw pinch reflex in the spontaneously breathing animals.

Positive pressure ventilation was performed using a specially designed, computer-controlled ventilator. ${ }^{5}$ Negative pressure ventilation with the required $\mathrm{V}_{\mathrm{T}}$ and timing was obtained by means of an adjustable negative pressure source and computer-controlled valve group connected to perspex chambers containing either the whole body or its upper part only, in which case a rubber diaphragm was made to fit the animal's body just below the xiphoid process. In spontaneously breathing animals, application of the diaphragm alone had little constraining effects, as lung elastance increased by approximately $2 \%$. Ports in the chamber walls provided the connections to the tracheal cannula, esophageal balloon, venous catheter, and rectal probe.

To ensure the same volume history and alveolar recruitment, two inflations at Ptr of approximately $20 \mathrm{~cm} \mathrm{H}_{2} \mathrm{O}$ were performed before the collection of mechanical measures (fig. 1, hatched areas). Lung dynamic elastance ( $\mathrm{EL}_{\mathrm{L}}$ ) and resistance $\left(\mathrm{R}_{\mathrm{L}}\right)$ were computed using the subtraction method for SV, NPwвMV, and NPтоMV groups, ${ }^{21}$ and the rapid end-inflation occlusion method for PPMV group, ${ }^{5}$ whereas chest-wall elastance (Ew) was computed according to the subtraction method in all but the SV group. The difference between the end-expiratory and residual volume was assessed by connecting the expiratory port to a drum in which pressure was set at $-10 \mathrm{~cm} \mathrm{H}_{2} \mathrm{O}$ and used as an index of EELV. After the 4-h ventilation period, all animals were subjected to PPMV for about $7 \mathrm{~min}$ (crossed area in fig. 1), for the assessment of pulmonary and chest-wall quasistatic elastance (Est,L and Est,w, respectively), interrupter resistance of the lung (Rint,L; essentially airway resistance), respiratory viscoelastic resistance (Rvisc,rs), and time constant ( $\tau$ visc,rs) according to the rapid end-inflation occlusion method, as previously described. ${ }^{5}$ Two inflation pressure-volume curves were also obtained by slowly inflating (approximately $1 \mathrm{ml} / \mathrm{s}$ ) the respiratory system to a Ptr of $40 \mathrm{~cm} \mathrm{H}_{2} \mathrm{O}$.

After collection of 1.5 to $2 \mathrm{ml}$ of blood from the heart (point B in fig. 1), the animals were killed with an overdose of anesthetic, the main left bronchus was cannulated, and the left lung removed, weighed immediately, lavaged with $4.3 \mathrm{ml} / \mathrm{kg}$ of normal saline in two aliquots, left overnight in an oven at $120^{\circ} \mathrm{C}$, and weighed again to compute the wetto-dry ratio (W/D). The effluents were pooled, centrifuged (Harrier 18/80; Sanyo Gallenkamp PLC, Loughborough, 


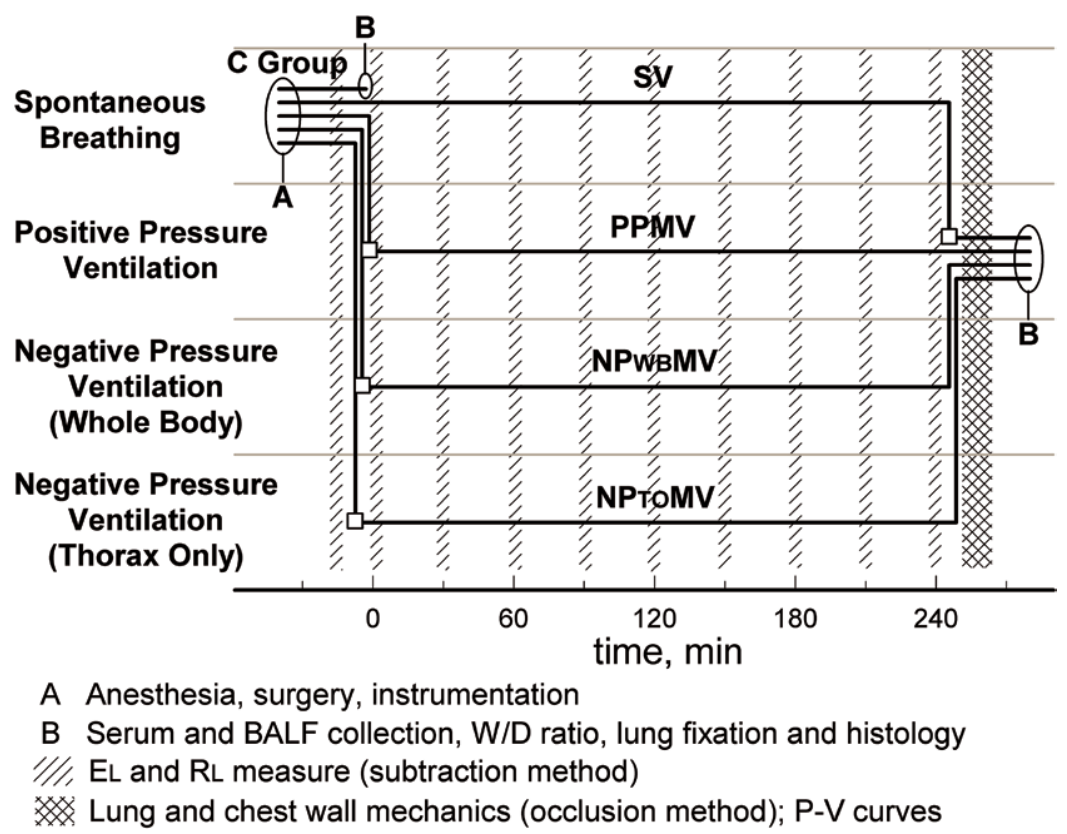

Fig. 1. Timeline representation of the main procedures used in rats subjected to various ventilation modes. The animals of the control group (C group) were killed immediately after the initial period of spontaneous ventilation. Squares indicate induction of paralysis. BALF = broncho-alveolar lavage fluid; $\mathrm{E} L$ and $\mathrm{R} L$ = lung dynamic elastance and resistance; NPTOMV or NPwBMV, PPMV, and SV = groups of animals that underwent $4 \mathrm{~h}$ of thorax-only or whole-body negative pressure ventilation, positive pressure mechanical ventilation, and spontaneous ventilation, respectively; $\mathrm{P}-\mathrm{V}=$ respiratory system pressure-volume curves; W/D = lung wet-to-dry ratio.

United Kingdom) at 2,000 rpm for $10 \mathrm{~min}$, and the supernatant was frozen and stored at $-20^{\circ} \mathrm{C}$.

Cytokine (tumor necrosis factor- $\alpha$, interleukin [IL]-1 $\beta$, IL-6, and IL-10, macrophage inflammatory protein-2) analysis and assessment of albumin concentration was carried out in duplicate in blinded fashion on BALF and serum, as previously described. ${ }^{6}$ Sandwich enzyme immunoassay of E-Selectin was performed using goat anti-rat E-selectin antibodies (R\&D Systems Inc., Minneapolis, MN). Absorbance was read at $405 \mathrm{~nm}$. A pool of sera from 20 anesthetized healthy rats was used as the standard control, and the readings from individual specimens were expressed as percent of control.

The right lung was fixed by intratracheal instillation of a $8 \%$ formaldehyde, $0.1 \%$ glutaraldehyde solution with the pressure maintained at $20 \mathrm{~cm} \mathrm{H}_{2} \mathrm{O}$ for $24 \mathrm{~h}$, and processed for histological examination according to standard methods, as previously described. ${ }^{5,6,22}$ Histologic evaluation was performed in a blind fashion by a single observer by using an image analysis system (IMAQ; National Instruments, Austin, TX). The following measures were obtained (1) mean linear intercept $(\mathrm{Lm})$, a measure of air-space enlargement, and its coefficient of variation as a measure of dispersion; (2) percent ratio of abnormal to total (normal and abnormal) bronchiolar-alveolar attachments, and distance between normal attachments as indices of airway-parenchymal mechanical uncoupling; (3) percent ratio of lesioned (epithelial necrosis and sloughing) to total membranous bronchioles, the bronchiolar injury score, as an index of small airway injury; (4) percent ratio of cuffed to total arterioles
(50 to $250 \mu \mathrm{m}$ in diameter) as an additional index of edema; and (5) polymorphonuclear leukocyte count in the alveolar septa as an index of parenchymal inflammation.

\section{Statistics}

Analyses were performed using SPSS 18.0 (SPSS Inc., Chicago, IL). Results are presented as mean \pm SD for mechanical parameters, W/D and BALF to serum albumin concentration ratio, and as median and range for cytokine and E-selectin concentration, and histologic parameters. The sample size was based on preliminary observations of the variables examined in previous studies ${ }^{15-17}(\mathrm{~W} / \mathrm{D}$, polimorphonuclear count, dynamic $\mathrm{P}_{\mathrm{L}}$ ). Comparisons of pressure-volume curves, breathing patterns, and mechanical parameters during prolonged ventilation with various modes were performed using mixed-, between-, and within-group factorial ANOVA for repeated measurements. One-way ANOVA was used to detect between-group differences for final measures of respiratory mechanics, W/D and BALF to serum albumin concentration ratios. In all instances, two-tailed testing was performed. Analysis of nonparametric variables was made with the Kruskal-Wallis and Mann-Whitney test. When post hoc tests were performed, the Bonferroni correction was applied. The level for statistical significance was taken at $P$ value 0.05 or less.

\section{Results}

Breathing pattern $\left(V_{\mathrm{T}}, \mathrm{T}_{\mathrm{I}}\right.$, and $\left.\mathrm{T}_{\mathrm{E}}\right)$ and lung mechanics (EL and $\mathrm{R}_{\mathrm{L}}$ ) did not differ statistically among the various groups, 
during the initial period of spontaneous breathing (table 1). In 40 animals, $\mathrm{V}_{\mathrm{T}}$, both absolute and per kg body weight, $\mathrm{T}_{\mathrm{I}}, \mathrm{T}_{\mathrm{E}}, \mathrm{EL}_{\mathrm{L}}$, and $\mathrm{R}_{\mathrm{L}}$ averaged $2.52 \pm 0.25 \mathrm{ml}, 6.2 \pm 0.6 \mathrm{ml} / \mathrm{kg}$, $0.23 \pm 0.01 \mathrm{~s}, 0.44 \pm 0.07 \mathrm{~s}, 1.89 \pm 0.41 \mathrm{~cm} \mathrm{H}_{2} \mathrm{O} / \mathrm{ml}$, and $0.111 \pm 0.026 \mathrm{~cm} \mathrm{H}_{2} \mathrm{O} s \mathrm{ml}^{-1}$, respectively.

\section{Prolonged and Final Ventilation Period}

Lung dynamic elastance was similar in the SV, PPMV, and NPwвMV groups, but larger in the NPтоMV group by approximately $60 \%$ at all points in time $(P=0.001)$; it increased progressively in all groups by the same relative amount $(P<0.001)$, which averaged $17 \pm 15 \%$ (fig. 2$)$. In contrast, $\mathrm{R}_{\mathrm{L}}$ was constant and similar in all groups (fig. 2; $P=0.342,0.538$, and 0.591 for time, time group, and group, respectively). Ew was also time independent; it did not differ significantly between the PPMV and NPwвMV group $(0.81 \pm 0.27$ and $0.72 \pm 0.25 \mathrm{~cm} \mathrm{H} \mathrm{O} / \mathrm{ml} ; P=0.515)$, but was markedly larger in the NPтоMV group $(1.29 \pm 0.39 \mathrm{~cm}$ $\left.\mathrm{H}_{2} \mathrm{O} / \mathrm{ml} ; P=0.005\right)$. EELV was similar in all groups $(P=0.873)$, and time independent $(P=0.878)$, averaging $1.96 \pm 0.28 \mathrm{ml}$ and $1.99 \pm 0.28 \mathrm{ml}$ at the beginning and end of the ventilation period, respectively.

When respiratory system mechanics was reassessed during the final PPMV period (fig. 1, crossed area), no statistically significant differences in Est,L, Est,w, Rint,L, Rvisc,rs, and $\tau$ visc,rs were found among the four groups (table 2). Similarly, the inflation pressure-volume curves of the respiratory system, chest wall, and lungs of the various groups were almost superimposed (fig. 3).

\section{W/D Ratio, Albumin BALF to Serum Ratio, and Cytokines}

No difference in the W/D ratio and that between BALF and serum albumin concentration occurred among groups ( $P=0.846$ and $P=0.169$, respectively), indicating that interstitial or alveolar edema was absent. The mean values of these variables were $4.24 \pm 0.25 \%$ and $0.70 \pm 0.48 \%$, respectively.

Cytokine concentrations in serum and BALF and serum levels of E-selectin are shown in figure 3. Serum concentration of IL-1 $\beta$, IL-6, and IL-10 in the SV, PPMV, NPwвMV, and NPтоMV groups was significantly higher than that of $C$ group, whereas that of IL- $1 \beta$ and IL-10 was higher in the NPтоMV than SV, PPMV, and NPwвMV groups, in which it was similar. In BALF, no statistically significant changes from control levels were observed, except for IL- $1 \beta$ and IL-6 concentration in NPTоMV group, which were increased significantly. Serum E-selectin concentration was similar in C, SV, PPMV, and NPwвMV, but significantly higher in the NPTоMV group.

\section{Histology}

The results of histologic measurements are reported in table 3 . None of the measured variables differed significantly among the various groups, except polimorphonuclear leukocyte count. Indeed, the number of polymorphonuclear leukocytes in the alveolar septa per unit length of the alveolar wall was similar in groups SV, PPMV, and NPwBMV $(P=0.318)$, lower in group $\mathrm{C}(P=0.004$ or less $)$, and higher in group NPTоMV $(P<0.001)$ than in SV, PPMV, and NPwвMV groups. In all groups, no signs of focal alveolar collapse, edema, or hemorrhage were present.

Table 1. Breathing Pattern and Lung Mechanics during the Initial 10-min Period of Spontaneous Breathing

\begin{tabular}{|c|c|c|c|c|c|c|c|}
\hline Group & $\mathrm{n}$ & $\mathrm{VT}, \mathrm{ml}$ & $\mathrm{VT}, \mathrm{ml} / \mathrm{kg}$ & $\mathrm{TI}, \mathrm{s}$ & $\mathrm{TE}, \mathrm{s}$ & $\mathrm{EL}, \mathrm{cm} \mathrm{H} \mathrm{H}_{2} \mathrm{O} / \mathrm{ml}$ & $\mathrm{RL}, \mathrm{cm} \mathrm{H}_{2} \mathrm{O} \cdot \mathrm{s} \cdot \mathrm{ml}^{-1}$ \\
\hline C & 8 & $2.4 \pm 0.2$ & $6.0 \pm 0.3$ & $0.23 \pm 0.02$ & $0.48 \pm 0.06$ & $1.92 \pm 0.32$ & $0.128 \pm 0.027$ \\
\hline SV & 8 & $2.6 \pm 0.4$ & $6.5 \pm 0.9$ & $0.22 \pm 0.02$ & $0.40 \pm 0.05$ & $1.81 \pm 0.39$ & $0.116 \pm 0.026$ \\
\hline PPMV & 8 & $2.6 \pm 0.2$ & $6.4 \pm 0.3$ & $0.22 \pm 0.01$ & $0.42 \pm 0.04$ & $1.75 \pm 0.40$ & $0.108 \pm 0.022$ \\
\hline NPwBMV & 8 & $2.5 \pm 0.2$ & $5.9 \pm 0.7$ & $0.24 \pm 0.02$ & $0.43 \pm 0.12$ & $1.94 \pm 0.62$ & $0.094 \pm 0.027$ \\
\hline NPтоMV & 8 & $2.5 \pm 0.2$ & $6.0 \pm 0.7$ & $0.23 \pm 0.03$ & $0.45 \pm 0.11$ & $2.03 \pm 0.35$ & $0.109 \pm 0.025$ \\
\hline$P$ value & & 0.314 & 0.314 & 0.207 & 0.321 & 0.718 & 0.075 \\
\hline
\end{tabular}

Values are mean $\pm \mathrm{SD}$.

$\mathrm{C}=$ group of animals killed immediately after the $10 \mathrm{~min}$ of spontaneous ventilation; EL and RL = lung dynamic elastance and resistance; NPTOMV or NPWBMV, PPMV, and SV = groups of animals that subsequently underwent $4 \mathrm{~h}$ of thorax-only or whole-body negative pressure ventilation, positive pressure mechanical ventilation, and spontaneous ventilation, respectively; TI and TE = inspiratory and expiratory duration; VT = tidal volume.

Table 2. Respiratory Mechanics Assessed during the Short, Final Period of Positive Pressure Mechanical Ventilation

\begin{tabular}{lcccccc}
\hline Group & $\mathrm{n}$ & Est, L, $\mathrm{cm} \mathrm{H}_{2} \mathrm{O} / \mathrm{ml}$ & Est, $\mathrm{w}, \mathrm{cm} \mathrm{H} \mathrm{H}_{2} \mathrm{O} / \mathrm{ml}$ & Rint,L, $\mathrm{cm} \mathrm{H}_{2} \mathrm{O} \cdot \mathrm{s} \cdot \mathrm{ml}^{-1}$ & Rvisc,rs, $\mathrm{cm} \mathrm{H}_{2} \mathrm{O} \cdot \mathrm{s} \cdot \mathrm{ml}^{-1}$ & $\tau \mathrm{visc}, \mathrm{rs}, \mathrm{s}$ \\
\hline SV & 8 & $1.39 \pm 0.25$ & $0.60 \pm 0.17$ & $0.096 \pm 0.020$ & $0.48 \pm 0.14$ & $1.33 \pm 0.18$ \\
PPMV & 8 & $1.41 \pm 0.39$ & $0.58 \pm 0.12$ & $0.077 \pm 0.021$ & $0.52 \pm 0.13$ & $1.60 \pm 0.42$ \\
NPWBMV & 8 & $1.28 \pm 0.42$ & $0.60 \pm 0.12$ & $0.094 \pm 0.016$ & $0.40 \pm 0.10$ & $1.10 \pm 0.42$ \\
NPTOMV & 8 & $1.44 \pm 0.25$ & $0.53 \pm 0.16$ & $0.078 \pm 0.017$ & $0.52 \pm 0.06$ & $1.37 \pm 0.28$ \\
$P$ value & & 0.793 & 0.720 & 0.086 & 0.160 & 0.054 \\
\hline
\end{tabular}

Values are mean $\pm \mathrm{SD}$.

Est, L and Est, $w$ = quasistatic lung and chest-wall elastance; NPTOMV or NPWBMV, PPMV, and SV = groups of animals that underwent $4 \mathrm{~h}$ of thorax-only or whole-body negative pressure ventilation, positive pressure mechanical ventilation, and spontaneous ventilation, respectively; Rint, $L=$ lung interrupter resistance; Rvisc,rs and $\tau$ visc, rs = respiratory system viscoelastic resistance and time constant. 

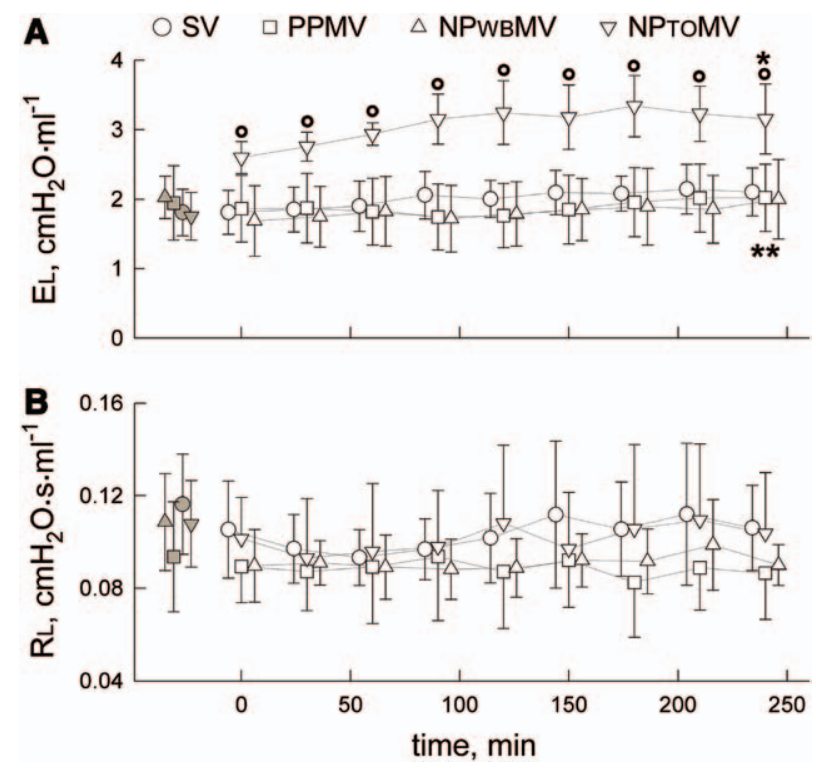

Fig. 2. Lung mechanical properties during the $4 \mathrm{~h}$ period of spontaneous ventilation (SV), positive pressure mechanical ventilation (PPMV), and whole-body (NPwBMV) or thorax-only negative pressure ventilation (NPTOMV). ( $A$ ) Dynamic elastance $(\mathrm{EL})$, and $(B)$ resistance $(\mathrm{R} \mathrm{L})$. Closed symbols indicate values obtained during the preceding $10 \mathrm{~min}$ of spontaneous breathing. Symbols were shifted slightly along the time axis to avoid excessive overlapping. Bars: SD; ${ }^{\star} P<0.05$ and ${ }^{\star \star} P<0.01$, significantly different from the corresponding value at $t=0 ;{ }^{\circ} P<0.01$, significantly different from the corresponding values of the other groups.

\section{Discussion}

This study in healthy rats has investigated the effects of different types of prolonged ventilation that occurred with the same $\mathrm{V}_{\mathrm{T}}$, timing, and EELV of the anesthetized, spontaneously breathing animal, showing that: (1) compared with spontaneous breathing, PPMV causes neither lung damage nor inflammatory reaction; (2) NPwвMV is equivalent to PPMV; and (3) NPтоMV induces lung distortion and a mild inflammatory response.

No change in lung mechanical properties occurred because of prolonged SV, PPMV, or NPwBMV (figs. 2 and 3 ; table 2), though differences could have resulted from lung distortion due to different changes between spontaneous and positive pressure ventilation of the vertical gradient of $\mathrm{P}_{\mathrm{L}},{ }^{23}$ rib cage dimensions in anesthetized rabbits and dogs, ${ }^{24}$ and regional diaphragmatic displacement in anesthetized humans. ${ }^{25}$ On the contrary, NPTOMV should have caused a kind of cylindrical deformation of the lungs, ${ }^{26}$ as the rib cage expanded and the abdominal content shifted cranially with each inflation; indeed, EL increased immediately with NPтоMV, remained increased throughout the $4 \mathrm{~h}$ of mechanical ventilation (fig. 2), and returned to normal on removal of distortion (table 2). Similar distortion should also occur in dogs and humans, as can be inferred from the smaller pressure changes required to produce equal changes in EELV with positive end-expiratory pressure than grid and wrap devices or cuirass. ${ }^{27-29}$ Furthermore, lung distortion
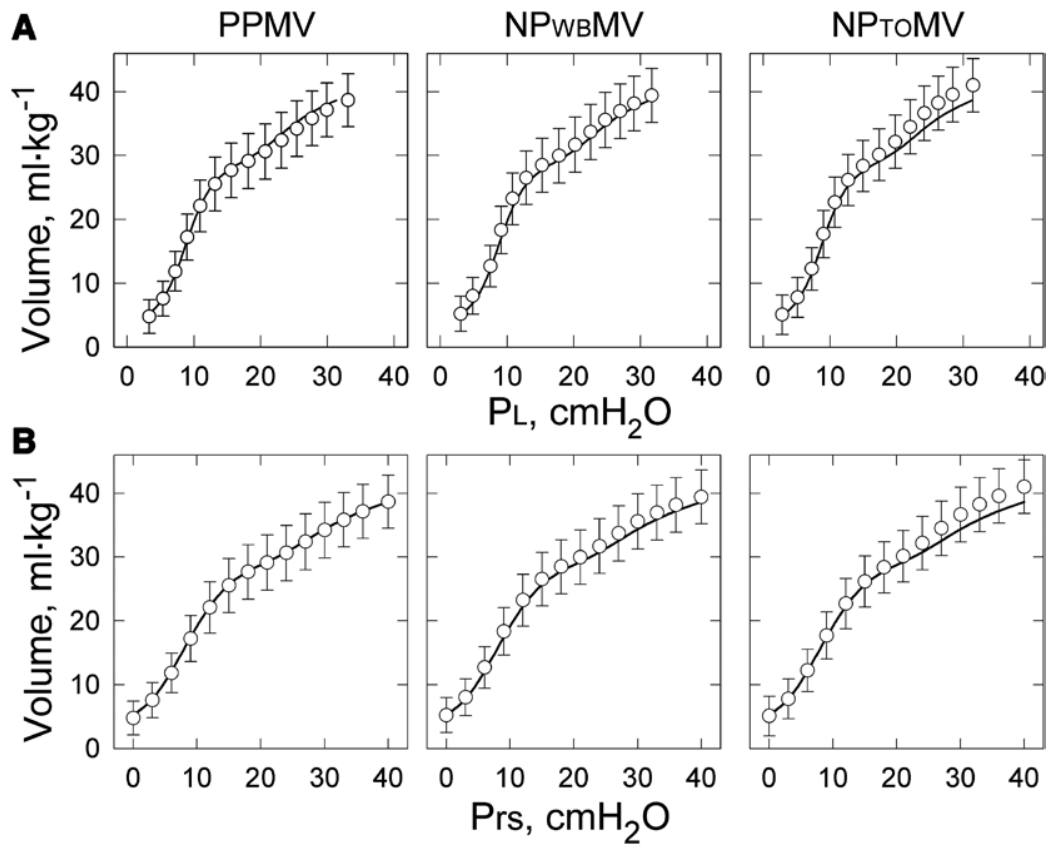

Fig. 3. Quasistatic inflation pressure-volume curves of lung $(A)$ and respiratory system $(B)$ obtained after $4 \mathrm{~h}$ of spontaneous ventilation (continuous line in all panels), positive pressure mechanical ventilation (PPMV), and whole-body (NPwBMV) or thoraxonly negative pressure ventilation (NPTOMV). PL and Prs, transpulmonary pressure and pressure across the respiratory system, respectively. Both for $\mathrm{PL}-$ and Prs-volume curves, no significant difference was found among groups $(P=0.628$ and $P=0.542$, respectively). Bars: SD. 
Table 3. Indexes of Parenchymal, Airway, and Vascular Damage

\begin{tabular}{lcccccccc}
\hline Group & $\mathrm{n}$ & $\mathrm{Lm}, \mu \mathrm{m}$ & $\mathrm{CVLm}, \%$ & $\mathrm{~A}-\mathrm{A}, \%$ & $\mathrm{D}, \mu \mathrm{m}$ & $\mathrm{IS}$ & $\mathrm{PAC}, \%$ & $\mathrm{PMN}, \mathrm{mm}^{-1}$ \\
\hline C & 8 & $69(60-73)$ & $16(13-22)$ & $3(2-6)$ & $51(41-58)$ & $6.1(5-8)$ & $5(0-14)$ & $0.4^{*}(0.4-0.7)$ \\
SV & 8 & $67(63-67)$ & $16(14-19)$ & $4(2-4)$ & $51(42-52)$ & $6.6(5-8)$ & $5(2-7)$ & $0.8(0.5-1.3)$ \\
PPMV & 8 & $65(64-70)$ & $16(13-18)$ & $4(3-5)$ & $50(41-57)$ & $6.2(5-9)$ & $2(0-30)$ & $1.2(0.5-1.3)$ \\
NPWBMV & 8 & $70(61-75)$ & $16(13-19)$ & $3(2-5)$ & $50(44-56)$ & $6.5(5-8)$ & $3(0-10)$ & $1.2(0.7-1.5)$ \\
NPTOMV & 8 & $61(54-76)$ & $19(16-22)$ & $5(2-6)$ & $52(50-57)$ & $6.3(5-9)$ & $0(0-15)$ & $3.0^{*}(1.8-3.4)$ \\
$P$ value & & 0.585 & 0.299 & 0.585 & 0.610 & 0.984 & 0.650 & $<0.001$ \\
\hline
\end{tabular}

Values are medians with range in parentheses.

* Significantly lower $(P=0.004$ or less) or higher $(P<0.001)$ than any other group.

$\mathrm{A}-\mathrm{A}=$ percentage of abnormal alveolar-bronchiolar attachments; $\mathrm{C}=$ group of animals killed immediately after the 10 min of spontaneous ventilation; $\mathrm{D}=$ distance between normal alveolar-bronchiolar attachments; IS = bronchiolar injury score; Lm and CVLm = mean linear intercept and its coefficient of variation; NPTOMV or NPWBMV, PPMV, and SV = groups of animals that underwent $4 \mathrm{~h}$ of thorax-only or whole-body negative pressure ventilation, positive pressure mechanical ventilation, and spontaneous ventilation, respectively; PAC = periarteriolar cuffs; PMN = polymorphonuclear leukocytes in the alveolar septa per millimeter of alveolar wall length.

can induce cyclic closing and opening of small airways despite preserved EELV, with possible epithelial cell damage and cytokine release. ${ }^{4-6,30}$

In contrast with the findings of Mead and Collier ${ }^{31}$ in dogs and present results in rats (fig. 2), Moriondo et al. ${ }^{15}$ have reported that for the same $V_{T}$, PL swings are fivefold larger in mechanically ventilated than spontaneously breathing rats, implying a nearly seven times greater EL with PPMV. These results are difficult to explain. Such very large swings of PL were observed only in surfactant-depleted, open-chest rats and rabbits during PPMV at zero end-expiratory pressure, and were associated with markedly greater W/D and BALF to serum albumin concentration ratio, heavy signs of airway and parenchymal damage, and prominent inflammatory response. ${ }^{6,32}$

The effects produced by NPwвMV never differed from those with PPMV (table 3 and fig. 4), as predictable on the basis of the similar increases of $\mathrm{PL}_{\mathrm{L}}$ and $\mathrm{Pw}$, which also ensure

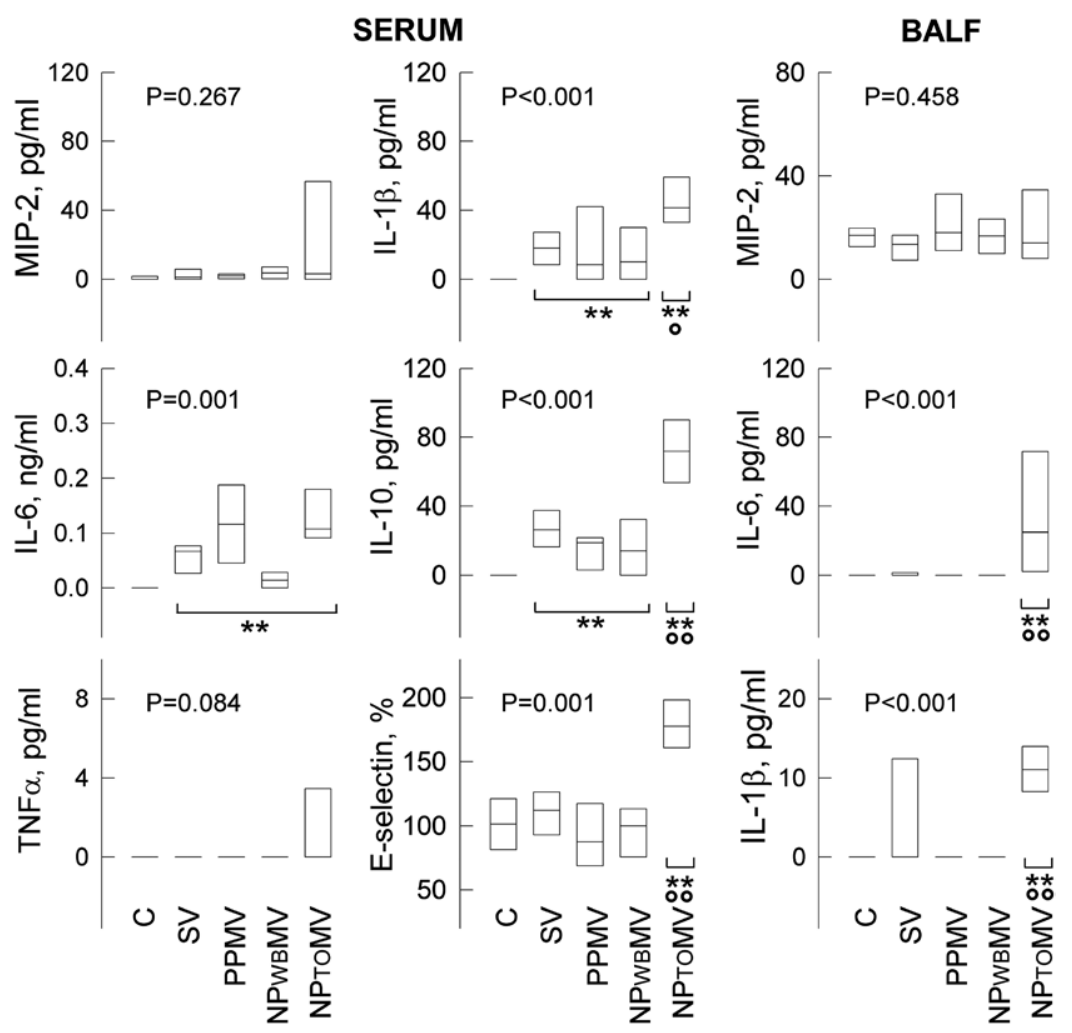

Fig. 4. Box-plot (median, 25 to 75th percentiles) of cytokine concentration in serum and broncho-alveolar lavage fluid (BALF) and E-selectin in serum of rats killed immediately (C), or subjected to a $4 \mathrm{~h}$ period of spontaneous ventilation (SV), positive pressure mechanical ventilation (PPMV), and whole-body negative (NPwBMV) or thorax-only negative pressure ventilation (NPTOMV). $P$ values in panels pertain to Kruskal-Wallis test; ${ }^{\star} P<0.05,{ }^{\star \star} P<0.01$, significantly different from $\mathrm{C}$ group; ${ }^{\circ} P<0.05$ and ${ }^{\circ} \mathrm{P}<0.01$, significantly different from SV, PPMV, and NPWBMV groups. IL = interleukine; MIP = macrophage inflammatory protein; TNF- $\alpha=$ tumor necrosis factor- $\alpha$. 
similar cardiovascular responses. ${ }^{33}$ Indeed, the differences between negative and positive pressure ventilation reported by Grasso et al. ${ }^{19}$ were not reproduced by a recent study. ${ }^{34}$

PPMV and NPwвMV neither impaired the integrity of the alveolar-capillary barrier, because both the W/D and BALF to serum albumin concentration ratio were similar to those of the C and SV group, nor caused histologic evidence of airway, parenchymal, and vascular damage (table 3). Serum levels of IL-1 $\beta$, IL- 6 , and IL-10 were, however, higher in the PPMV and NPwвMV than C group, but similar to those of the SV group (fig. 4), consistent with previous findings of similar tumor necrosis factor $\alpha$, IL-6, IL-10, and keratinocyte-derived chemokine concentration in serum or lung homogenates of spontaneously breathing and mechanically ventilated rats. ${ }^{35}$ The same applies to recruitment of polymorphonuclear leukocytes in the alveolar septa (table 3), suggesting that inflammatory response during SV, PPMV, and NPwвMV is related to anesthesia, surgery, and/or animal's instrumentation. ${ }^{36}$ Hence, the comparison of cytokines levels between control and mechanically ventilated animals can lead to an erroneous evaluation of the proinflammatory effects of mechanical ventilation. This may have happened in the studies on mice, where the SV group was lacking, ${ }^{16}$ or different doses of anesthetics had been administered. ${ }^{17}$ Furthermore, it seems unlikely that the discrepancy between these and present studies can be attributed to the somewhat longer period of mechanical ventilation used in mice, ${ }^{16,17}$ because increased expression of inflammatory cytokines in BALF macrophages of rats and increase of pulmonary and systemic cytokine levels in mice are already observed within 120 and $60 \mathrm{~min}$ from the onset of PPMV with noninjurious tidal volumes. ${ }^{14,16}$ At any rate, the kind of response to PPMV observed in mice vanished completely after $24 \mathrm{~h} .{ }^{16}$

In contrast with PPMV and NPwвMV, NPтоMV elicited a significant increase of polymorphonuclear leukocyte count in the alveolar septa (table 3), as well as of IL-1 $\beta$, IL-10, and E-selectin concentration in serum and IL-1 $\beta$ and IL-6 concentration in BALF relative to corresponding levels in the SV group (fig. 4). The presence of IL-1 $\beta$ and IL- 6 in BALF was probably the consequence of local production in the airspaces, because their BALF and serum concentrations did not correlate $(P>0.70)$, consistent with the preserved integrity of the alveolar-capillary barrier. Cytokines release with NPтоMV cannot be attributed to anesthesia, surgery, animal's instrumentation, and breathing pattern, because they were the same in all groups. A possible explanation can be provided by the presence with NPTOMV of lung distortion, leading to proinflammatory cytokine release via cellular mechanotransduction. ${ }^{10,11}$ This inflammatory response, however, had no apparent, short-term consequences, because none of the functional and morphological variables differed among all groups at the end of the experiments, (tables 2 and 3 ). However, it remains to be seen whether with a more protracted $\mathrm{NP}_{\mathrm{T}} \mathrm{MV}$, the inflammatory reaction can eventually cause mechanical and/or histologic alterations.
Interestingly, serum E-selectin, an endothelial cell adhesion molecule mediating leukocyte rolling and phagocyte chemotaxis, ${ }^{37}$ was increased with NPToMV only, and its levels did in fact correlate with the degree of lung distortion $(P=0.035)$ indexed by the ratio between $\mathrm{EL}_{\mathrm{L}}$ at the onset of NPтоMV and the preceding SV period. This suggests that distortion could have activated the endothelial cells by changing their shape either directly or through alterations of the blood flow regime in their proximity. ${ }^{38,39}$

In conclusion, both prolonged positive and negative pressure ventilation performed in normal animals with the $V_{T}$ and timing of spontaneous, quiet breathing neither elicit a proinflammatory response nor cause functional and morphological alterations. In view of the adverse effects of conventional mechanical ventilation with large tidal volumes, this supports the notion of the presence of a critical volume threshold above which acute lung injury ensues. However, an inflammatory reaction with cytokines production and/ or release can be induced by distortion of the pulmonary parenchyma, even in the absence of volotrauma in normal lungs, as it occurs with poncho-like devices. This could have important implications in the presence of pathological, heterogeneous alterations of lung mechanics, when distortion can be induced by conventional positive pressure ventilation in spite of the use of low tidal volumes.

\section{Acknowledgments}

Support was provided solely from institutional and/or departmental sources.

\section{Competing Interests}

The authors declare no competing interests.

\section{Correspondence}

Address correspondence to Dr. D'Angelo: Dipartimento di Fisiopatologia Medico-chirurgica e dei Trapianti, Università degli Studi di Milano, via Mangiagalli 32, 20133 Milan, Italy. edgardo.dangelo@unimi.it. Information on purchasing reprints may be found at www.anesthesiology.org or on the masthead page at the beginning of this issue. Anesthesiology's articles are made freely accessible to all readers, for personal use only, 6 months from the cover date of the issue.

\section{References}

1. Faridy EE, Permutt S, Riley RL: Effect of ventilation on surface forces in excised dogs' lungs. J Appl Physiol 1966; 21:1453-62

2. Webb HH, Tierney DF: Experimental pulmonary edema due to intermittent positive pressure ventilation with high inflation pressures. Protection by positive end-expiratory pressure. Am Rev Respir Dis 1974; 110:556-65

3. Dreyfuss D, Saumon G: Ventilator-induced lung injury: Lessons from experimental studies. Am J Respir Crit Care Med 1998; 157:294-23

4. Muscedere JG, Mullen JB, Gan K, Slutsky AS: Tidal ventilation at low airway pressures can augment lung injury. Am J Respir Crit Care Med 1994; 149:1327-34 
5. D'Angelo E, Pecchiari M, Baraggia P, Saetta M, Balestro E, Milic-Emili J: Low-volume ventilation causes peripheral airway injury and increased airway resistance in normal rabbits. J Appl Physiol (1985) 2002; 92:949-56

6. D'Angelo E, Koutsoukou A, Della Valle P, Gentile G, Pecchiari M: Cytokine release, small airway injury, and parenchymal damage during mechanical ventilation in normal open-chest rats. J Appl Physiol (1985) 2008; 104:41-9

7. Tremblay L, Valenza F, Ribeiro SP, Li J, Slutsky AS: Injurious ventilatory strategies increase cytokines and c-fos m-RNA expression in an isolated rat lung model. J Clin Invest 1997; 99:944-52

8. von Bethmann AN, Brasch F, Nüsing R, Vogt K, Volk HD, Müller KM, Wendel A, Uhlig S: Hyperventilation induces release of cytokines from perfused mouse lung. Am J Respir Crit Care Med 1998; 157:263-72

9. Ricard JD, Dreyfuss D, Saumon G: Production of inflammatory cytokines in ventilator-induced lung injury: A reappraisal. Am J Respir Crit Care Med 2001; 163:1176-80

10. Haitsma JJ, Uhlig S, Göggel R, Verbrugge SJ, Lachmann U, Lachmann B: Ventilator-induced lung injury leads to loss of alveolar and systemic compartmentalization of tumor necrosis factor-alpha. Intensive Care Med 2000; 26:1515-22

11. Vogel V, Sheetz M: Local force and geometry sensing regulate cell functions. Nat Rev Mol Cell Biol 2006; 7:265-75

12. Tremblay LN, Slutsky AS: Ventilator-induced lung injury: From the bench to the bedside. Intensive Care Med 2006; 32:24-33

13. Crotti S, Mascheroni D, Caironi P, Pelosi P, Ronzoni G, Mondino M, Marini JJ, Gattinoni L: Recruitment and derecruitment during acute respiratory failure: A clinical study. Am J Respir Crit Care Med 2001; 164:131-40

14. Kotani N, Takahashi S, Sessler DI, Hashiba E, Kubota T, Hashimoto H, Matsuki A: Volatile anesthetics augment expression of proinflammatory cytokines in rat alveolar macrophages during mechanical ventilation. ANESTHESIOLOGY 1999; 91:187-97

15. Moriondo A, Pelosi P, Passi A, Viola M, Marcozzi C, Severgnini P, Ottani V, Quaranta M, Negrini D: Proteoglycan fragmentation and respiratory mechanics in mechanically ventilated healthy rats. J Appl Physiol (1985) 2007; 103:747-56

16. Vaneker M, Halbertsma FJ, van Egmond J, Netea MG, Dijkman HB, Snijdelaar DG, Joosten LA, van der Hoeven JG, Scheffer GJ: Mechanical ventilation in healthy mice induces reversible pulmonary and systemic cytokine elevation with preserved alveolar integrity: An in vivo model using clinical relevant ventilation settings. ANESTHESIOLOGY 2007; 107:419-26

17. Wolthuis EK, Vlaar AP, Choi G, Roelofs JJ, Juffermans NP, Schultz MJ: Mechanical ventilation using non-injurious ventilation settings causes lung injury in the absence of preexisting lung injury in healthy mice. Crit Care 2009; 13:R1

18. Reiss LK, Kowallik A, Uhlig S: Recurrent recruitment manoeuvres improve lung mechanics and minimize lung injury during mechanical ventilation of healthy mice. PLoS One 2011; 6:e24527

19. Grasso F, Engelberts D, Helm E, Frndova H, Jarvis S, Talakoub O, McKerlie C, Babyn P, Post M, Kavanagh BP: Negativepressure ventilation: Better oxygenation and less lung injury. Am J Respir Crit Care Med 2008; 177:412-8

20. Baydur A, Behrakis PK, Zin WA, Jaeger M, Milic-Emili J: A simple method for assessing the validity of the esophageal balloon technique. Am Rev Respir Dis 1982; 126:788-91
21. Mead J, Whittenberger JL: Physical properties of human lungs measured during spontaneous breathing. J Appl Physiol 1953; 5:779-96

22. D'Angelo E, Pecchiari M, Saetta M, Balestro E, Milic-Emili J: Dependence of lung injury on inflation rate during low-volume ventilation in normal open-chest rabbits. J Appl Physiol (1985) 2004; 97:260-8

23. D'Angelo E, Agostoni E: Continuous recording of pleural surface pressure at various sites. Respir Physiol 1973; 19:356-68

24. D'Angelo E, Michelini S, Miserocchi G: Local motion of the chest wall during passive and active expansion. Respir Physiol 1973; 19:47-59

25. Froese AB, Bryan AC: Effects of anesthesia and paralysis on diaphragmatic mechanics in man. ANESTHESIOLOGY 1974; 41:242-55

26. D'angelo E: Stress-strain relationships during uniform and non uniform expansion of isolated lungs. Respir Physiol $1975 ; 23: 87-107$

27. Borelli M, Benini A, Denkewitz T, Acciaro C, Foti G, Pesenti A: Effects of continuous negative extrathoracic pressure versus positive end-expiratory pressure in acute lung injury patients. Crit Care Med 1998; 26:1025-31

28. Lockhat D, Langleben D, Zidulka A: Hemodynamic differences between continual positive and two types of negative pressure ventilation. Am Rev Respir Dis 1992; 146:677-80

29. Scholz SE, Knothe C, Thiel A, Hempelmann G: Improved oxygen delivery by positive pressure ventilation with continuous negative external chest pressure. Lancet 1997; 349:1295-6

30. Pecchiari M, Monaco A, Koutsoukou A, D’Angelo E: Plasma membrane disruptions with different modes of injurious mechanical ventilation in normal rat lungs*. Crit Care Med 2012; 40:869-75

31. Mead J, Collier C: Relation of volume history of lungs to respiratory mechanics in anesthetized dogs. J Appl Physiol 1959; 14:669-78

32. D'Angelo E, Pecchiari M, Gentile G: Dependence of lung injury on surface tension during low-volume ventilation in normal open-chest rabbits. J Appl Physiol (1985) 2007; 102:174-82

33. Maloney JV Jr, Whittenberger JL: Clinical implications of pressures used in the body respirator. Am J Med Sci 1951; 221:425-30

34. Engelberts D, Malhotra A, Butler JP, Topulos GP, Loring SH, Kavanagh BP: Relative effects of negative versus positive pressure ventilation depend on applied conditions. Intensive Care Med 2012; 38:879-85

35. Kox M, Vaneker $M$, van der Hoeven JG, Scheffer GJ, Hoedemaekers CW, Pickkers P: Effects of vagus nerve stimulation and vagotomy on systemic and pulmonary inflammation in a two-hit model in rats. PLoS One 2012; 7:e34431

36. D'Angelo E, Pecchiari M, Della Valle P, Koutsoukou A, MilicEmili J: Effects of mechanical ventilation at low lung volume on respiratory mechanics and nitric oxide exhalation in normal rabbits. J Appl Physiol (1985) 2005; 99:433-44

37. Kumar P, Hosaka S, Koch AE: Soluble E-selectin induces monocyte chemotaxis through Src family tyrosine kinases. J Biol Chem 2001; 276:21039-45

38. Huang RB, Eniola-Adefeso O: Shear stress modulation of IL-1 $\beta$-induced E-selectin expression in human endothelial cells. PLoS One 2012; 7:e31874

39. Chiu JJ, Chen CN, Lee PL, Yang CT, Chuang HS, Chien S, Usami S: Analysis of the effect of disturbed flow on monocytic adhesion to endothelial cells. J Biomech 2003; 36:1883-95 